\title{
Groundwater
}

\author{
Review Paper/
}

\section{Assessing Groundwater Depletion and Dynamics Using GRACE and InSAR: Potential and Limitations}

\author{
by Pascal Castellazzi ${ }^{1}$, Richard Martel ${ }^{2}$, Devin L. Galloway ${ }^{3}$, Laurent Longuevergne ${ }^{4}$, and Alfonso Rivera ${ }^{5}$
}

\begin{abstract}
In the last decade, remote sensing of the temporal variation of ground level and gravity has improved our understanding of groundwater dynamics and storage. Mass changes are measured by GRACE (Gravity Recovery and Climate Experiment) satellites, whereas ground deformation is measured by processing synthetic aperture radar satellites data using the InSAR (Interferometry of Synthetic Aperture Radar) techniques. Both methods are complementary and offer different sensitivities to aquifer system processes. GRACE is sensitive to mass changes over large spatial scales (more than $100,000 \mathrm{~km}^{2}$ ). As such, it fails in providing groundwater storage change estimates at local or regional scales relevant to most aquifer systems, and at which most groundwater management schemes are applied. However, InSAR measures ground displacement due to aquifer response to fluid-pressure changes. InSAR applications to groundwater depletion assessments are limited to aquifer systems susceptible to measurable deformation. Furthermore, the inversion of InSAR-derived displacement maps into volume of depleted groundwater storage (both reversible and largely irreversible) is confounded by vertical and horizontal variability of sediment compressibility. During the last decade, both techniques have shown increasing interest in the scientific community to complement available in situ observations where they are insufficient. In this review, we present the theoretical and conceptual bases of each method, and present idealized scenarios to highlight the potential benefits and challenges of combining these techniques to remotely assess groundwater storage changes and other aspects of the dynamics of aquifer systems.
\end{abstract}

${ }^{1}$ Corresponding author: Institut national de la recherche scientifique, Centre Eau, Terre et Environnement, Université du Québec, 490 rue de la Couronne, Québec, OC, Canada G1K 9A9; (418) 570-3630; fax: (418) 654-2600; pascal.castellazzi@ete.inrs.ca

${ }^{2}$ Institut national de la recherche scientifique, Centre Eau, Terre et Environnement, Université du Québec, 490 rue de la Couronne, Québec, QC, Canada G1K 9A9; (418) 654-2683; fax: (418) 654-2600; richard.martel@ete.inrs.ca

${ }^{3}$ United States Geological Survey, Water Science Field Team - West, 5957 Lakeside Boulevard, Indianapolis, IN 462780000; (916) 801-2040; dlgallow@usgs.gov

${ }^{4}$ Géosciences Rennes, UMR CNRS 6118. Université Rennes 1, Campus Beaulieu. 35042 Rennes Cedex, France; (33) 223236 546; laurent.longuevergne@univ-rennes1.fr

${ }^{5}$ Geological Survey of Canada, Natural Resources Canada, 490, rue de la Couronne, Quebec, QC, Canada G1K 9A9; (418) 654-2688; fax: (418) 654-2615; alfonso.rivera@canada.ca

Received March 2016, accepted July 2016.

(c) 2016, National Ground Water Association.

doi: $10.1111 /$ gwat.12453

\section{Introduction}

Groundwater systems play a central role in sustaining ecosystems and providing humanity with high-quality freshwater (Taylor et al. 2013). The reliance on groundwater will probably intensify under climate change, as it affects precipitation patterns, and as adaptation strategies generally rely on groundwater resources (Kundzewicz et al. 2007; Green et al. 2011), pointing out the necessity of adequate observation tools for management.

As a diffusive media storing water, groundwater systems respond to natural and human-induced changes in external and internal boundary fluxes (recharge and discharge) by changes in storage and fluid pressure (head), which in turn affect flow. Groundwater depletion is one of the many objective and subjective factors used to determine the sustainability of groundwater resources. Overexploited aquifer systems typically exhibit groundwater depletion, that is, a long-term decrease in the 
volume of stored groundwater (Konikow 2015). Groundwater extraction modifies the groundwater flows to satisfy pumping rates. Groundwater storage decreases as water is released from storage; the groundwater system converges toward a new equilibrium constrained by the capture of available water sources, where capture refers to both potential increased recharge and decreased discharge. For a detailed discussion of capture and groundwater depletion, see Konikow and Leake (2014). Depending on what is deemed as acceptable consequences (environmental, economic, and social) of the groundwater depletion and the effects of any induced recharge or reduced discharge such as decreased springflow or streamflow or drying lakes and wetlands, the development and use of groundwater may or may not be considered sustainable (Alley et al. 1999; Armandine et al. 2014).

Large-scale monitoring of head and storage changes generally relies on temporal responses to natural and/or anthropogenic stresses, measured as water-level changes in wells. The distribution of monitoring wells is often sparse at the scale of the groundwater system, and individual wells tend to represent local conditions of the penetrated hydrogeologic units within the system. Two processes offer "distant" actions and allow observations of groundwater behavior and its spatial variability from the surface or from space. The first one is gravity: water storage changes directly contribute to the changes in the mass balance and induce temporal variations of the gravity field (Pool 2008). For example, repeated microgravity observations at the land surface measure changes in local water mass assuming other mass changes are not significant. The second one is poro-elastic deformation; head changes induce media deformation that can be measured at the surface (e.g., Chaussard et al. 2014a; Schuite et al. 2015). These two distant actions might be measured remotely: InSAR (Interferometry of Synthetic Aperture Radar) measures Earth's surface deformation and GRACE (Gravity Recovery and Climate Experiment) mission (Tapley et al. 2004; Schmidt et al. 2008) is sensitive to water mass changes. Both observation systems offer a new vision on groundwater response to anthropic and climatic pressures and the impact of heterogeneity on flow patterns. This paper addresses the potential and synergy of the two remote sensing tools to monitor the sustainable use of groundwater resources. The methods and prospective approaches presented in the following sections focus on enhancing estimates of groundwater depletion at aquifer scale that can be used by water resource managers and stakeholders to formulate criteria for the sustainable use of groundwater systems.

\section{Groundwater Depletion}

Groundwater storage change ( $\Delta$ GWS $)$ can be computed using a water-budget (mass balance) approach for a specified nonequilibrium accounting period (usually annual or multiannual), where $\Delta$ GWS is the residual of aquifer-system inflows and outflows (Equation 1):

$$
\Delta \mathrm{GWS}=R-(D+P)
$$

where $R$ is the rate of groundwater recharge, $D$ is the groundwater discharge rate, and $P$ is the net rate of extraction from pumping. Another common approach uses changes in water levels to compute $\Delta \mathrm{GWS}$ (Equation 2):

$$
\Delta \mathrm{GWS}=\Delta h A S
$$

where $\Delta h$ is the change in water level (expressed as hydraulic head) for some specified time, $A$ is the area of the aquifer representative of the head change, and $S$ is the aquifer storage coefficient or storativity. This approach is used in numerical groundwater flow models on a per model-cell basis to compute cell-by-cell and integrated $\Delta \mathrm{GWS}$ for the model domain. Both approaches generally rely on typically inaccurate and sparsely available field data to constrain the $\Delta \mathrm{GWS}$ estimates, which is exacerbated by high heterogeneity of the geological media (Marsily et al. 2005), and difficulties in estimating recharge (Equation 1) and storativity (Equation 2).

\section{Aquifer Response: Confined vs. Unconfined}

To understand physical changes within depleting aquifers, it is important to examine aquifer storativity $(S)$, that is, the ratio between the volume of water taken into or released from storage per unit area of aquifer, per unit of hydraulic head change, which can be expressed by rearranging Equation 2 as (Equation 3):

$$
S=\Delta \mathrm{GWS} /(\Delta h A)
$$

$S$ can be calculated for unconfined (Equation 4) and confined aquifers (Equation 5):

$$
\begin{gathered}
S=S y+b S s \sim S y \\
S=b S s=b\left(S s_{k}+S s_{w}\right)=b\left(\rho g\left(\alpha+n \beta_{w}\right)\right)
\end{gathered}
$$

where $S y$ is the drainage porosity, also called unconfined storativity or specific yield, $b$ is the aquifer thickness, $S s$ is the specific storage coefficient $(S s=S / b), S s_{k}$ is the skeletal specific storage, related to aquifer matrix compressibility $(\alpha), S s_{w}$ is the water specific storage, related to water compressibility $\left(\beta_{w}\right), \rho$ is fluid density, $g$ is the gravitational acceleration, and $n$ is aquifer porosity. Note that because the development of the classical groundwater storage coefficient $(S)$ assumes onedimensional vertical stress and strain, the vertical ground displacement $\Delta u$ resulting from a change in vertical stress expressed in terms of $\Delta h$ can be defined as (Equation 6), where $\Delta u / b$ is the vertical strain:

$$
\Delta u=b S s \Delta h
$$

Typical values of storativity range from $5 \times 10^{-5}$ to $5 \times 10^{-3}$ (Todd 1980) in confined aquifers and 


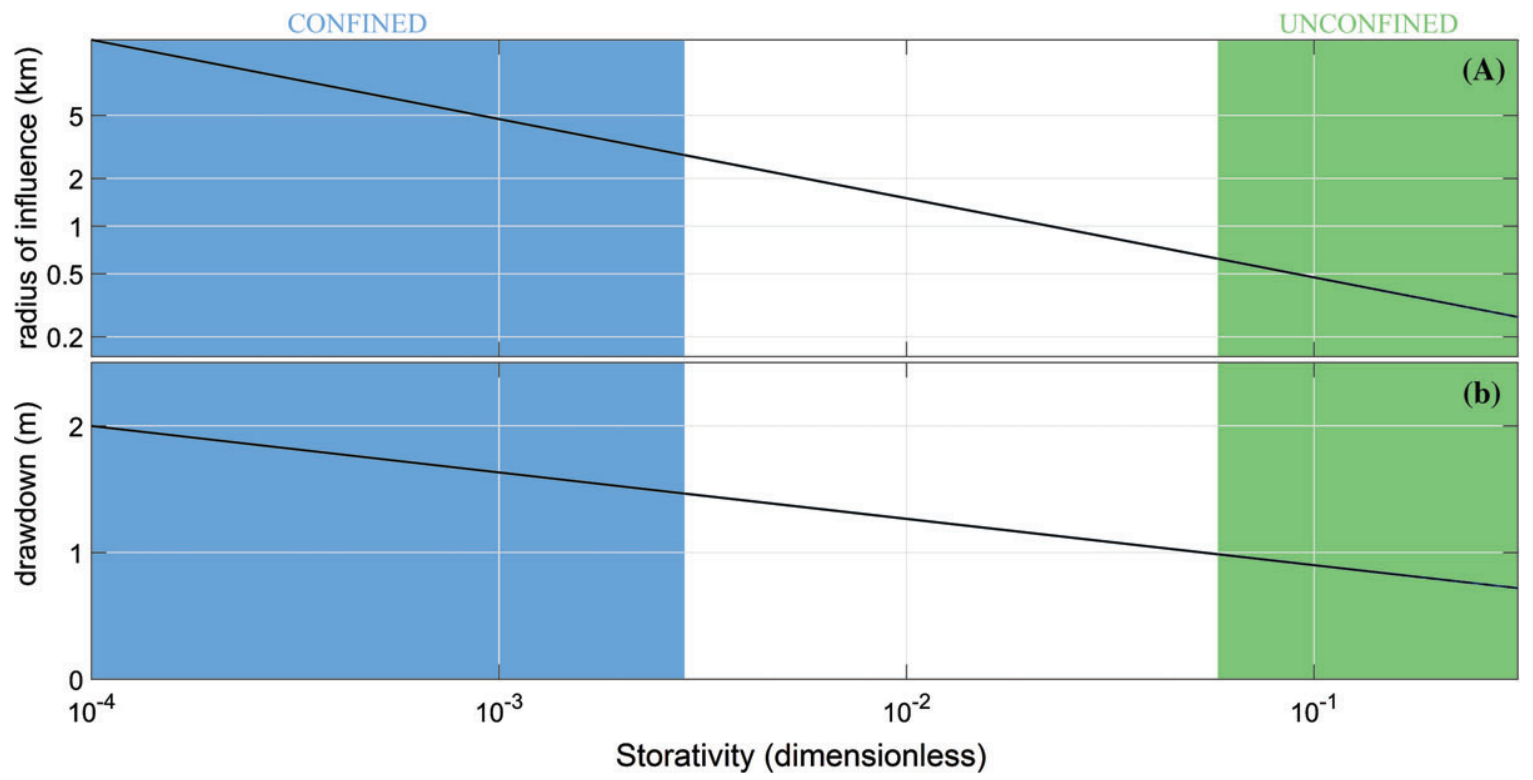

Figure 1. (A) Storativity vs. radius of influence according to the Cooper-Jacob approximation; (B) storativity vs. drawdown in an observation well located $50 \mathrm{~m}$ distant from a pumping well according to the Theis nonequilibrium equation. Typical values of storativity are highlighted in blue for confined conditions, and in green for unconfined conditions. Transmissivity is $100 \mathrm{~m}^{2} / \mathrm{d}, 100 \mathrm{~d}$ of pumping at a constant rate of $200 \mathrm{~m}^{3} / \mathrm{d}$.

$1.10^{-1}$ to $3.10^{-1}$ in unconfined aquifers (Lohman 1972); that is, unconfined storativity $(S y)$ is about two to four orders of magnitude larger than confined storage. The ideal aquifer response (drawdown, or $\Delta h$ ) to pumping at a specified rate in both types of aquifers of infinite extent (assuming similar hydraulic conductivity and other aquifer properties) results in a larger extension/volume of the cone of depression for confined aquifers. In other words, the change in storage ( $\Delta$ GWS) needed to supply the pumping volume is derived from a larger volume of the aquifer material for confined vs. unconfined conditions. This analysis applies to porous media only.

\section{Hydraulic Head Response}

The Cooper-Jacob solution is an approximation of the Theis (1935) nonequilibrium method for the calculation of the radius of influence of a steadily pumping well as a function of storativity and time in an ideal confined aquifer (Cooper and Jacob 1946; Dragoni 1998). It relies on the assumptions of horizontal isotropic, homogeneous aquifers of infinite extent, and fully penetrating wells. It can be used for unconfined aquifers with proper correction. Figure 1 shows the radius of influence (Figure 1A) and the drawdown $\left(h_{0}-h\right.$; where $h_{0}$ is the initial head prior to the imposed pumping stress) as a function of aquifer storativity $(S)$ using the Theis (Figure 1B) and the Cooper-Jacob (Figure 1B) solutions. Note that (1) the Cooper-Jacob solution should not be used for unconfined conditions without Jacob's correction for partial dewatering of water-table aquifers (e.g., transmissivity changes; see Halford et al. 2006) and (2) the Theis solution can be used for unconfined conditions only when the late-time segment of the Theis well function is considered (Theis 1935; Van der Kamp 1985; Kruseman and De Ridder
1991), that is, when the delayed water-table response can be overlooked.

The radius of influence, that is, the horizontal effect of head loss, increases strongly when storativity decreases (Figure 1A). The cone of depression is deeper near the pumping well and spreads more widely for confined vs. unconfined conditions. While the total mass change is equivalent for both cones of depression, the mass changes nearby the pumping center are larger for the unconfined aquifer compared with those for the confined aquifer. This partially explains good correlations between water levels and local microgravity measurements in areas near hydraulic stresses and in unconfined aquifers (Pool and Eychaner 1995; Pool 2008). For confined aquifer conditions, the correlation is poorer (Pool 2008), because mass changes are less concentrated in the near-field region around the pumping well.

\section{Aquifer System Compaction}

Groundwater depletion can lead to ground subsidence. Analysis and simulation of aquifer-system compaction have been addressed primarily using two approaches: One based on the conventional groundwater flow theory (Jacob 1940) and one based on the linear poro-elasticity theory (Biot 1941). The former approach is a special case of the latter, and both approaches are based on the principle of effective stress (Terzaghi 1925). For the discussions here, we follow the approach of Hoffmann et al. (2003b) based on the conventional groundwater flow theory. Assuming incompressible solid grains, and only vertical effective stresses and vertical strains, the effective stress principle can be expressed (Equation 7):

$$
\sigma \mathrm{t}=\sigma \mathrm{e}+p
$$


where $p$ is the interstitial fluid pressure, $\sigma_{\mathrm{t}}$ is the total vertical stress and $\sigma_{e}$ is the vertical effective stress. For the case of constant total stress (where $\Delta \sigma_{\mathrm{t}}=0$ ), Equation 6 can be simplified and expressed in terms of changes $(\Delta)$ in stress (Equation 8):

$$
\Delta \sigma \mathrm{e}=-\Delta p=-\rho g \Delta h
$$

where $\rho$ is the water density and $g$ is the gravitational constant.

The response of saturated geological media to increase in effective stress is governed by the matrix and fluid compressibilities embodied in the skeletal and water-specific storage terms constituting the aquifer storativity of the material (Equation 5). The most compressible and porous materials are clay and silt, and the least compressible have a compressibility of the same order of magnitude as water (Domenico and Mifflin 1965; Freeze and Cherry 1979). In these compressible materials, the effective stress increases the compression of the aquifer skeleton, decreasing porosity, and to a certain extent, decreasing $S s$ and hydraulic conductivity $(K)$. Additionally, compressible, typically low-permeability fine-grained units in layered heterogeneous aquifer systems play a major role in impeding vertical groundwater flow between more permeable, typically coarser-grained hydrogeologic units. Depending on the continuity of the fine-grained units and their position within the aquifer system, they usually form either confining units between aquifer systems or discontinuous interbeds within the aquifers. In overexploited unconfined aquifers, decrease in the effective stress occurs in underlying confined aquifers according to the decrease in geostatic stress. This phenomenon should be taken into account when interpreting or predicting ground displacements $(\Delta u)$ related to depleting unconfined aquifers (see Leake and Galloway 2007). For a more complete description and review of land subsidence caused by aquifer-system compaction, see Galloway and Burbey (2011).

\section{Detection of Groundwater Depletion}

\section{InSAR}

Several techniques are available to measure ground displacements, including primarily borehole extensometers, GPS (Global Positioning System), conventional surveying, Light Detection and Ranging (LiDAR), and InSAR. It is possible to monitor both trends and seasonal variations of the ground level and changes in groundwater storage with proper use of any of these techniques. InSAR is increasingly used in hydrogeology (Galloway and Hoffmann 2007; Galloway 2014) because of its precision reaching a few mm/year, its spatial coverage typically between 100 to $5000 \mathrm{~km}^{2}$, and its cost-efficiency.

\section{Principle and Application}

InSAR consists in interpreting phase shift between several SAR (Synthetic Aperture Radar) acquisitions taken from the same orbital track. Parameters influencing the phase shift, such as the perspective change resulting from the difference in satellite position in space between acquisitions (spatial baseline) and the atmospheric effects can be estimated and removed from the measured phase shift. The remaining phase shift component is the temporal change of the satellite Line Of Sight (LOS) distance.

There are currently three main InSAR processing workflows used in hydrogeological applications: Differential (D), Small Baseline Subset (SBAS), and Persistent Scatterers Interferometry (PSI). With the D-InSAR technique, two SAR images acquired at different times are used to create a phase shift map, called interferogram (Rocca et al. 1997; Massonnet and Feigl 1998). The phase difference map is wrapped over phase cycles $(-\pi$ to $+\pi)$, and can be converted to real displacement values using a spatial-phase unwrapping algorithm. The SBAS technique uses numerous (usually tens to hundreds) interferograms selected within all possible combination offered by several SAR acquisitions. The interferograms are produced and corrected following the D-InSAR approach, and the SBAS algorithm (Berardino et al. 2002; Lanari et al. 2004) is used to retrieve surface displacement through time along the SAR images timeseries. PSI is also a time-series technique but only the phase history of highly coherent and stable scattering targets is used (Ferretti et al. 2000, 2001). The spatial-phase unwrapping used in SBAS or D-InSAR is replaced by a temporal-phase unwrapping calculated for each target individually using the temporal history of the phase. Consequently, PSI provides a greater accuracy over persistent and coherent targets than do SBAS (Pasquali et al. 2011) but is limited to areas with a high density of stable targets (e.g., buildings or bedrock outcrops), making it less appropriate for nonurban settings (e.g., agricultural areas relying on groundwater-supplied irrigation).

Galloway and Hoffmann (2007) enumerate the main uses of InSAR in hydrogeology: (1) Identify lithostratigraphic and structural boundaries in groundwater-flow systems; (2) identify aquifer-system heterogeneity; (3) estimate aquifer-system hydromechanical properties; and (4) constrain numerical models of groundwater flow, aquifer-system compaction, and land subsidence. The most comprehensive use of InSAR in hydrogeology is its integration in flow model calibration (e.g., Hoffmann et al. 2003a; Yan and Burbey 2008; Siade et al. 2014). More recently, InSAR-derived ground displacement mapping has been used to (1) estimate storage change within a well-known lithological context (e.g., Chaussard et al. 2014b); (2) improve lithological knowledge and define specific geological structures such as fractures (e.g., Hernandez-Marin and Burbey 2009; Xu et al. 2012; Zhang et al. 2014; Castellazzi et al. 2016a); (3) predict future land subsidence rates (e.g., Calderhead et al. 2011); and (4) infer changes in hydraulic head after a calibration period relating ground and groundwater levels (Reeves et al. 2011; Chaussard et al. 2014b). 
Resolution, Accuracy, and Challenges

The availability of large variety of SAR sensors and the diversity of acquisition options in LOS angle, resolution, and coverage make the technique adaptable to detect displacement in almost any settings. SAR acquisitions have spatial resolution ranging from 1 to $50 \mathrm{~m}$ and extend over 10 to $200 \mathrm{~km}$ in both length and width (more strictly, azimuth and range).

In the case of D- and SBAS-InSAR, the resolution should be decreased by a factor of 2 to 5 to improve the signal/noise ratio and allow a consistent spatialphase unwrapping. The development of InSAR processing algorithms combined with the rising availability of large SAR images stacks allows routine monitoring of ground displacements, with an accuracy of 1 to $4 \mathrm{~mm} /$ year (e.g., Samsonov et al. 2010).

The main challenges of InSAR application to water science is linked to the loss of coherence in natural system (vegetated, agricultural areas). The loss of interferometric coherence is usually proportional to the vegetation height and inversely proportional to the SAR wavelength. Although patches of trees in urban settings are usually smoothened by down-sampling or are compensated by interpolating the final results, the lack of coherence is a problem where high vegetation is dominant throughout the land cover (e.g., crops, forest). For example, short wavelength SAR (e.g., $3.1 \mathrm{~cm}$ wavelength of TerraSAR$\mathrm{X}$ ) would not allow ground displacement detection in farmland and scrublands, and coherence would only be sufficient in urban settings. To overcome the problem, longer SAR wavelengths (e.g., $23 \mathrm{~cm}$ wavelength of ALOS-1/2) can be used at the cost of larger displacement detection threshold (around $1 \mathrm{~cm} /$ year) and a lower vertical precision. Atmospheric effects also affect InSAR results at the scale of up to few $\mathrm{mm} / \mathrm{year}$, but they can be almost completely taken into account while using recent sensors and methodological improvements (Ferretti et al. 2007; Rucci et al. 2012). In hydrogeology, the displacement detected by InSAR is often assumed to be entirely linked to aquifer compaction. At the $\mathrm{cm} / \mathrm{year}$ scale, the spatial patterns of aquifer compaction are usually well distinguishable from sediment erosion, sediment deposition, landslides, volcanism, or tectonic fault movements. Although the potential application arising by retrieving ground displacements at the $\mathrm{mm}$ /year scale is important (Schuite et al. 2015), their interpretation remains a challenge when several displacement causes may coexist.

The SAR phase should be comparable between successive acquisitions. If the differential movement between two acquisitions of a SAR time-series is higher than the length of a SAR wave phase, and if this movement is not spatially progressive, phase "jumps" occur and the inversion of the phase into displacement is compromised. For this reason, the temporal density of an InSAR images stack, that is, the time interval between images, should adequately match the expected displacement rates, which can often be roughly anticipated $( \pm 50 \%)$, considering the hydrogeological knowledge of the area, previous
InSAR studies, other available ground displacement measurements, or comparable cases. Ideally, to retrieve a constant subsidence rate of $5 \mathrm{~cm} /$ year with the original PSI technique (i.e., PSInSAR ${ }^{\mathrm{TM}}$; see Ferretti et al. 2001), the SAR time-series should be constructed of at least seven images per year in X-band, four images per year in C-band, and one image per year in L-band (wavelength of $3.1,5.6$, and $23 \mathrm{~cm}$, respectively). If the subsidence is spatially progressive, stronger subsidence rates can be retrieved through the spatial-phase unwrapping typically used in D and SBAS, and implemented in some PSI algorithms (see Crosetto et al. 2016). Other parameters should be taken into account, for example, the noise level of the SAR data, the phase unwrapping technique, and the temporal variability of the ground displacements. Consequently, a comfortable margin in the temporal density of the time-series is always preferred. Users should be aware that the temporal density of the acquisition forming a SAR time-series is limited by the orbital cycles of the spacecraft, usually from 10 to $46 \mathrm{~d}$. The recent Sentinel-1A and 1B system provides comparable images every $6 \mathrm{~d}$.

\section{Data Availability, Current Developments, and Future Missions}

Several space-borne SAR missions are currently operating: Radarsat-2 (C-band, Canadian Space Agency), Sentinel-1A and 1B (C-band, European Space Agency), TerraSAR-X (X-band, German Aerospace Center), COSMO-SkyMed (X-band, Italian Space Agency), and ALOS-2 (L-band, Japan Aerospace eXploration Agency). Archived SAR time-series from past or current missions are increasingly available at no cost. Data from ERS-1, ERS-2, and ENVISAT are available upon application (https://earth.esa.int). They are covering the periods 1991 to 2000,1995 to 2011 , and 2002 to 2011 , respectively. ALOS-1 data cover 2006 to 2011 and are available upon registration (https://www.asf.alaska.edu). From 2014, Sentinel-1 mission provides free and high-quality data to InSAR specialists (https://sentinel.esa.int or https://peps.cnes.fr).

Recent advancement in space-borne SAR sensor, as seen in the recent Sentinel mission, provides (1) an ever improving signal/noise ratio, allowing to produce and unwrap interferograms at full resolution and to retrieve fine spatial details of ground deformation; (2) a higher repeat path frequency, allowing, for example, to infer seasonal ground-level variations with high temporal details and relate them to seasonal recharge and discharge patterns; and (3) an increased spatial coverage, allowing, for example, its use at GRACE scale and related applications, as described in this article.

At least two new SAR missions are planned for launch in the next years: Radarsat Constellation (C-band, Canadian Space Agency) and NiSAR (L- and S-band, US National Aeronautics and Space Administration and The Indian Space Research Organisation). Some of the recent (e.g., Sentinel) and upcoming missions consist in positioning two to three SAR satellites on 
different orbital configurations, allowing to (1) cover the entire earth surface more frequently; (2) generate digital elevation model with large-baseline interferometry of two synchronous SAR acquisitions taken from different spacecraft; and (3) simulate an higher repeat path frequency to improve earth deformation monitoring with time-series InSAR.

\section{GRACE}

The GRACE satellite mission (Tapley et al. 2004) has provided new insights into mass redistribution within the Earth's system and offers new perspectives in hydrology.

\section{Principle and Application}

Similar to the first two satellites of its generation, GRACE is monitoring spatio-temporal changes in the Earth's gravity field with an unprecedented resolution, allowing interpretation of mass changes within hydrosystems (see e.g., Cazenave and Chen, 2010). The system comprises two satellites on an approximately $450 \mathrm{~km}$ altitude orbit track and about $200 \mathrm{~km}$ apart. Distance between the satellites is measured at the micrometer level, allowing detection of $1 \mathrm{~cm}$ water thickness equivalent (WTE) distributed over an area at the scale of the system's altitude, that is, with a diameter of a few hundred kilometers. Gravity has two fundamental advantages. First, the link between gravity and mass storage is direct, independent of lithology, and requires no calibration. Second, the distant effect allows to penetrate Earth at depth and record mass storage in groundwater systems. GRACE integrates vertically all water storage components. The groundwater contribution can be inferred by removing all other components from the total water storage change ( $\triangle$ TWS ) measured by GRACE (Equation 9):

$$
\Delta \mathrm{GWS}=\Delta \mathrm{TWS}-(\Delta \mathrm{SWS}+\Delta \mathrm{SMS}+\Delta \mathrm{SIS})
$$

where $\triangle \mathrm{SWS}$ is the surface water storage variations; $\triangle \mathrm{SMS}$ is the water storage variations in the soil unsaturated zone; and $\Delta$ SIS is the snow and ice water storage variations. In quantitative hydrogeology, the main difficulty of using GRACE is gathering enough field data and/or model output to account for surface-water, soil-moisture, and snow/ice storage. Typically, $\Delta$ SIS and $\Delta$ SWS can be estimated using in situ or satellite altimetry data, and $\triangle$ SMS can be estimated using largescale models (Land Surface Models - LSM). $\Delta$ SWS, $\Delta \mathrm{SMS}$, and $\Delta$ SIS contribute to uncertainties in GWS estimation.

Since 2002, GRACE has provided unique and decisive data to understand, monitor, and model continental water cycle and exchanges between storage compartments (continents, atmosphere, and oceans). GRACE allowed monitoring of groundwater storage changes in natural or engineered systems (e.g., Rodell et al. 2009; Famiglietti et al. 2011; Huang et al. 2012; Richey et al. 2015). The approach was validated by comparison with well data in various climatic contexts
(Scanlon et al. 2012; Shamsudduha et al. 2012; Feng et al. 2013; Forootan et al. 2014). Integration of GRACE data in groundwater studies includes the assimilation into models (as validation or calibration) to improve their predictive ability (Guntner et al. 2007; Zaitchik et al. 2008; Sun et al. 2012; Xie et al. 2012; Döll et al. 2012; Eicker et al. 2014; Hu and Jiao, 2015).

\section{Resolution, Accuracy, and Challenges}

GRACE is sensitive to large-scale storage changes. Several authors have suggested that GRACE data could be safely interpreted for basins of at least $200,000 \mathrm{~km}^{2}$, and with a sensitivity of approximately $10 \mathrm{~mm}$ (i.e., $\sim 2 \mathrm{~km}^{3}$ ). Yet, GRACE is not a regular remote-sensing tool, and it offers a gravitational resolution, that is, sensitive to mass. Several studies have shown that the same mass concentrated over small area are recoverable (Longuevergne et al. 2013; Tourian et al. 2015). Therefore, there are potential to monitor high storage variability, such as the recharge zone of an aquifer system (Huang et al. 2015).

GRACE range rate data (distances between the two satellites, Level-1B data) should be processed and converted into mass changes and water storage changes in WTE (Level-3 data) to be used for hydrological applications. The most common processing strategies rely on converting the signal into spherical harmonics coefficients (Stokes coefficients, Level 2). Then, the coefficients are combined to spatial domain over a grid and filtered. Because of their sensitivity to larger scales, computed mass changes are generally affected by amplitude loss and require rescaling to produce Level-3 data. Landerer and Swenson (2012) and Long et al. (2015) proposed the use of scaling factors based on a priori mass variations from LSM. In the recent years, with increasing experience of GRACE data, several novel processing strategies have arisen to improve the spatial resolution (e.g., Bruinsma et al. 2010; Ramillien et al. 2011; Save et al. 2012). Among them, mass concentration solutions, or "mascons", are particularly suited for hydrological applications (e.g., Watkins et al. 2015; Sakumura et al. 2016). Intercomparison of different products has been recently carried out by Farinotti et al. (2015) and shows the large potential of these new datasets to work at scales closer to the groundwater management scale (scales $\sim 100,000 \mathrm{~km}^{2}$ ). For details on GRACE TWS processing to extract GWS contribution, associated uncertainties linked to GRACE large-scale sensitivity (truncation, filtering, and leakage), and estimation of storage compartments (Equation 9), the interested reader can refer to Longuevergne et al. (2010), Scanlon et al. (2012), and Long et al. (2016).

\section{Data Availability, Current Developments, and Future Missions}

Several versions of GRACE data are available online and free of charge. Official solutions from The Center for Space Research (CSR; Austin, Texas), The Jet Propulsion Laboratory (JPL; Pasadena, California), and The GFZ German Research Centre for Geosciences (GFZ; Potsdam, 

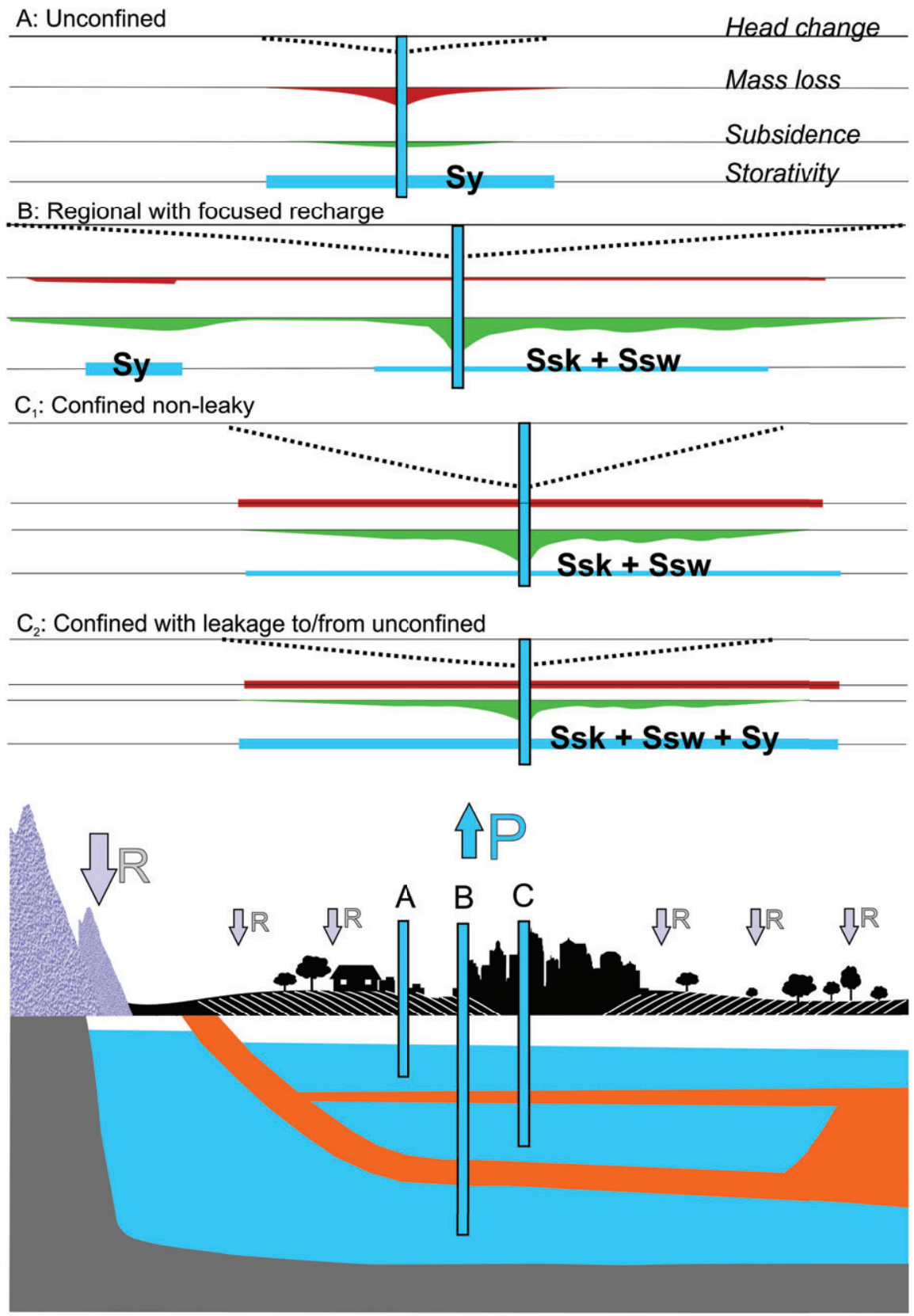

Figure 2. Conceptual models of land subsidence and mass losses occurrence in different idealized depleting aquifers. 'P: Pumping; R: Recharge.'

Germany) are popular (see http://gracetellus.jpl.nasa. gov/). Other solutions are available online at The Institute of Theoretical Geodesy and Satellite Geodesy (Graz University of Technology, Austria) and The Research Group for Space Geodesy (GRGS, French National Space Center) websites. The University of Colorado and GRGS created interactive portals to compute GRACE time-series over a region, a country, or a watershed (http://geoid. colorado.edu/grace and http://thegraceplotter.com/).

The use of GRACE in hydrogeology is still limited to the largest systems, for which it can be considered as one of the observation system in the hydrogeologist's toolbox (Alley and Konikow 2015). For further application and resolution of scientific challenges, the main limitations of GRACE are the limited spatial resolutions as well as the limited length of the available observations (see e.g., Scanlon et al. 2015). A recent consensus on the science and user needs for future satellite gravity observing systems has been synthetized in Pail et al. (2015). Waiting for the next generation of satellite gravity missions, the GRACE follow-on mission is planned for 2017.

\section{Theoretical Scenarios}

Identical groundwater withdrawal and use in each situation results in identical storage change volumes when integrated across the system area, while the spatial distributions of storage changes and compaction can be 
different for each case (Figure 2). In this section, the differences are discussed for three typical and theoretical types of hydrogeological settings, where water is extracted from an unconfined aquifer (A), from the confined part of a regional aquifer $(\mathrm{B})$, and from a confined $\left(\mathrm{C}_{1}\right)$ or semi-confined aquifer $\left(\mathrm{C}_{2}\right)$.

In an unconfined aquifer (Figure 2A), groundwater is extracted from the unconfined storage or drainage porosity $(S y)$, the radius of influence due to pumping is focused on the pumping center, and is smaller compared with a confined aquifer setting (see the effect of confinement on the radius of influence in Figure 1), that is, mass losses would be detectable by microgravity measurements located near the pumping center. InSAR and GRACE could both detect groundwater depletion if water is pumped beyond the sustainable rate and for InSAR only the portion of the storage change causing detectable deformation of the aquifer system manifested at the ground surface. Often, the return flows of the nonconsumptive-use fraction of the extracted groundwater are difficult to assess and may not be properly accounted in groundwater budgets (see e.g., Foster et al. 2004). Observations of aquifer storage change should help resolve other water budget components because GWS is typically treated as a residual of other components. Observations of GWS will help resolve other components, specifically net recharge rates.

Regional aquifer systems with spatially concentrated recharge (Figure 2B) generally occur in unconsolidated sedimentary (alluvial and fluvial) basins, where finegrained sediments with low permeability occur in lowlands and highly coarse and permeable sediments occur in the higher elevation and slopes (e.g., Calderhead et al. 2012). These basins typically are susceptible to aquifersystem compaction and land subsidence. Often, urban developments and groundwater extraction take place in the lowest altitude of the valley. In these settings, mass losses attributed to groundwater storage changes over the area of head loss would be diffusely spread throughout the confined aquifer (larger radius of influence). In this section of the aquifer, and if it is susceptible to compaction, the detectable gravity change could be attributable in part to aquifer compaction. There are two mechanisms of gravity change in compacting aquifers, elevation change and mass change. Elevation change is linked to the storage derived from compaction, while gravity change is a measure of total storage change if corrected for elevation change. The area of hydraulic head changes (see Figure 1B) may spread to the recharge area, which lead to head decline in the unconfined section of the aquifer, and where head changes correlate well with mass losses. Additionally, head losses in the pumping area can be partially compensated by regional flows. However, given that the typical groundwater transport times over large areas covered by GRACE are of long duration, this regionalscale adjustment to the pumping area does not likely affect the reliability of $\triangle \mathrm{GWS}$ assessment from GRACE. In such settings, the water budget should integrate a wider area, encompassing recharge and discharge areas, and integrating spatially variable inflows and outflows. Compaction of susceptible aquifer systems typically occurs nearby pumping areas, where detection through local microgravity measurements corresponds to the change in groundwater storage derived principally from skeletal storage $\left(S s_{\mathrm{k}}\right)$ and the change in land-surface altitude (Pool 2008). Both InSAR and microgravity measurements will be sensitive to spatial variability in the response of the aquifer system, while GRACE would integrate the whole affected area.

In a closed, nonleaky, confined, and fossil aquifer (Figure $2 \mathrm{C}_{1}$ ), extracted groundwater is derived from the confined storage, that is, the matrix and fluid compressibilities embodied in $S_{\mathrm{sk}}$ and $S_{\mathrm{sw}}$, respectively. Mass losses spread horizontally as a result of low storativity (large radius of influence, see Figure 1), any compaction, and resulting land subsidence are similarly distributed. The water balance (Equation 1) is inexorably negative. Because the groundwater resource in this aquifer is finite, consumptive uses of the groundwater constitute groundwater mining, though some return flow of nonconsumptively used groundwater extracted from the aquifer could replenish a shallow, hydraulically isolated overlying unconfined aquifer. The negative balance for the confined aquifer could theoretically be detectable by GRACE, but this measurement would be confounded by any storage changes in soil moisture and/or an overlying unconfined aquifer. InSAR alone cannot be used to determine the state of the water balance for that system, but can provide evidence of groundwater depletion in the confined aquifer (inelastic compaction and largely irreversible land subsidence) in affected areas within the system. The volume of land subsidence mapped using InSAR could be used as an estimate of the volume of largely irreversible storage depletion owing to the inelastic compressibility of the aquifer skeleton.

When the same type of aquifer receives water derived from leakage of an overlying unconfined aquifer (Figure $2 \mathrm{C}_{2}$ ), the horizontal spread of drawdowns, mass losses, and compaction are limited proportionally to the leakage.

\section{Potential Benefits of Combining GRACE and InSAR}

In the perspective of enhancing the capabilities of both techniques, we discuss four different potential approaches based on their combination.

\section{Toward High Resolution and Volumetric Groundwater Depletion Mapping}

The global volumetric and high spatial resolution mapping of groundwater storage changes is needed to fully support groundwater governance and assure sustainability of groundwater resources. Toward this objective, and where aquifer-system compaction is systematically linked to groundwater storage loss, InSAR can be used to partially overcome GRACE resolution limitations (Castellazzi et al. 2016b). 
InSAR-derived groundwater depletion mapping can be used as a quantitative or nonquantitative synthetic data as input into GRACE GWS change estimates. Indeed, while scaling factors derived from soil moisture models fail in downscaling GRACE-derived GWS trend maps, InSAR provides the proper downscaling data. The injection of InSAR measurement into GRACE data assumes that the reaction hydraulic head/compaction is stable throughout a large study area. Additionally, InSAR can also be inserted into the GRACE estimates as a groundwater depletion detection tool in a nonquantitative manner, providing only a spatial a priori of mass loss concentrations for GRACE GWS trend maps. Such approach was tested with success for glacier mass losses detection using GRACE (Farinotti et al. 2015). In all cases, sufficiently compressible hydrogeologic units need to be present throughout the study area and drawdown should be large enough to induce compaction and subsidence within the detectability range of InSAR. Another limitation of such approach resides in the confusion between climatic and anthropogenic GWS change in GRACE data.

\section{Remote Assessment of Aquifer Reaction to Pumping}

Both short-term fluctuations (daily-to-seasonal) and long-term trends of groundwater levels can cause temporal variations in aquifer-system deformation and accompanying land-surface movements. Early applications of InSAR to detect aquifer-system compaction and land subsidence focused on demonstrating the utility of the InSAR technique (e.g., Galloway et al. 1998; Amelung et al. 1999; Galloway et al. 2000; Hoffmann et al. 2001, 2003a; Lu and Danskin 2001; Heywood et al. 2002; Schmidt and Bürgmann 2003) to evaluate seasonal and interannual trends in compaction and the governing parameters controlling the hydromechanical response, principally to groundwater extractions, but also to natural recharge (Lu and Danskin 2001). The development of robust time-series InSAR methods greatly enhanced the potential for the monitoring of elastic and seasonal landsurface movements (e.g., with the SBAS-InSAR method: Reeves et al. 2011, 2014; Chaussard et al. 2014b). After a calibrating period of a few years using paired observations of water level variations and ground displacements, it is possible to infer seasonal water level changes by monitoring elastic ground displacements, provided that the water level variations are within the previously calibrated range of seasonal variations, and that the effective stress does exceed the preconsolidation stress. By replacing in situ measurements by GRACE-derived GWS variations, it would be possible to relate ground deformation with larger scale groundwater-storage changes with limited field data available. The approach shows potential for (1) estimating water level changes within the elastic range of deformation in areas devoid of monitoring wells and (2) detecting transgression from an elastic deformation accompanying seasonal head variations above critical preconsolidation heads. However, three main challenges remain: (1) InSAR should be applied over large areas commensurate with the GRACE scale (e.g., Chaussard et al. 2014a); (2) GRACE and InSAR should measure variations of the same water stocks; and (3) the spatial heterogeneity of aquifer-system storativity can be accounted for.

\section{Anthropogenic/Climatic Storage Changes}

Although InSAR and GRACE are used to map groundwater storage changes at different scales, the increasing availability of SAR data now allow the production of ground motion maps at the GRACE scale (e.g., Chaussard et al. 2014a). Furthermore, the increased sensitivity brought by recent InSAR developments (Rucci et al. 2012) shows great potential for ground motion detection induced by nonanthropogenic water storage change, likely slower than for groundwater depletion nearby pumping centers. As InSAR is not directly quantitative, there is a limited interest of using it alone. However, InSAR would be able to provide perspective on the relative importance of the anthropogenic and nonanthropogenic components of a given water storage change integrated by GRACE over a larger area. For such application: (1) the anthropogenic groundwater depletion areas have to be limited and well-defined throughout a typical GRACE footprint and (2) compressible hydrogeologic units should be sufficiently present throughout the study area. The nonanthropogenic storage change and induced ground motion are expected to be close to or smaller than the typical InSAR detection threshold of few 3 to $5 \mathrm{~mm} /$ year (PSI method and C-band radar data). As a result, the most important parameter for such application is the precision of InSAR measurement in natural settings. Atmospheric patterns influence radar waves. As this influence can be accounted for, this is still the major sources of error within InSAR measurements. Rucci et al. (2012) explains how a submillimeter precision could be obtained in the near future, in settings with large density of coherent ground targets and using the most recent SAR systems. Density of such targets is typically low in natural settings: Motion detection with high precision in natural settings is still a major challenge for InSAR specialists.

\section{Toward the Remote Assessment of Aquifer Confinement and Dynamics}

As shown on Figure 2, the spatial extent of mass loss and land subsidence depend on aquifer confinement. The ideal height for monitoring individual aquifers using gravity methods in order to minimize contributions from storage change in adjacent areas would be less than the half-width of the aquifer. Because most aquifers are smaller than can be individually monitored from the height of satellite orbits, airborne gravity methods would be most applicable. However the current development of higher resolution spaceborne gravimetric sensors (Thales Alenia Space 2010; Famiglietti and Rodell 2013; Watkins et al. 2013), there is great hope for detecting mass changes at local to regional scales. Thus, through comparison between theoretical concepts (see Figure 2) and case studies, hydrogeologists could potentially infer aquifer 
configuration and flow dynamics through spatial analysis of subsidence and mass losses occurrence.

\section{Summary}

In this review, we presented the general principles of two methods to remotely assess groundwater storage changes through gravity changes and aquifer-system compaction. While compaction measurements (e.g., InSAR) rely principally on the presence of fine-grained (clays and silts) compressible hydrogeologic units to reveal storage change, gravimetric methods (depending on their resolution) can be sensitive to aquifer confinement. Compaction occurs as a consequence of hydraulic pressure drop and the matrix compressibility of aquifer-system material, while gravity variations occur as a consequence of fluid mass changes, and to a certain extent, changes in the position of land surface owing to compaction and accompanying land subsidence.

Land subsidence detection takes advantage of a variety of resolutions, image footprint and precision options from several SAR imaging spacecraft currently operating. Imaging options range from semi-continental scales (e.g., ScanSAR or TOPSAR modes in ALOS-2 or Sentinel-1 satellites) to city scales (e.g., Radarsat-2 Ultrafine mode). Vertical precision usually ranges from millimeters when using short waves (e.g., X-band used by TerraSAR-X, $3.1 \mathrm{~cm}$ wavelength) to centimeters when using longer waves (L-band used by ALOS PALSAR, $23 \mathrm{~cm}$ wavelength). Shorter waves allow better vertical precision, while longer waves allow better detection in less coherent areas (e.g., farmland).

Although no studies exist on the remote detection of aquifer-system confinement through the analysis of land subsidence spatial patterns, we argue that this is theoretically possible with minimal lithological data. Indeed, because of the important difference in storativity, confined aquifers show ampler radius of influence and head drop than unconfined aquifers, which could reflect on amplitude and extent of land subsidence. Case studies in well-known hydrogeological settings, where in situ data are available, would allow to better understand the remaining challenges of such applications.

Microgravity surveys are costly, labor intensive, and spatially limited. GRACE data are freely available and of increasing ease of use, but because of the minimum critical area of usability, it is unsuitable at most typical aquifer scales. While microgravity measurements can provide information on local aquifer flow dynamics and confinement, GRACE does not. As none of these methods' resolution matches adequately the typical water management scales, there is a methodological gap left to be fulfilled.

The possibility of combining gravity and subsidence measurements to better assess aquifer dynamics shows potential, but is currently limited by methodological issues. Nevertheless, there is both hope and expectations for a valid option in the future regarding the remote assessment of aquifer confinement and groundwater flow dynamics.

\section{Acknowledgments}

The authors thank the Ministère des Relations Internationales Francophonie et Commerce Extérieur du Québec (MRIFCE, Québec) and the Consejo Nacional de Ciencia y Tecnología (CONACyT, Mexico) for their financial support. Additionally, the authors thank Luc Aquilina, René Lefebvre, and Jasmin Raymond, who initiated the collaboration between Institut National de la Recherche Scientifique in Québec and University of Rennes 1 in France. Through the creation of a Laboratoire International Associé (LIA) France-Québec, they made this research possible.

Authors' Note: The authors do not have any conflicts of interest or financial disclosures to report.

\section{References}

Alley, W.M., and L.F. Konikow. 2015. Bringing GRACE down to Earth. Groundwater 53, no. 6: 826-829.

Alley, W.M., T.E. Reilly, and O.L. Franke. 1999. Sustainability of ground-water resources. U.S. Geological Survey Circular 1186. http://pubs.usgs.gov/circ/circ1186/pdf/circ1186.pdf (accessed January 10, 2016).

Amelung, F., D.L. Galloway, J.W. Bell, H.A. Zebker, and R.J. Laczniak. 1999. Sensing the ups and downs of Las Vegas: InSAR reveals structural control of land subsidence and aquifer-system deformation. Geology 27, no. 6: 483-486.

Armandine Les Landes, A., L. Aquilina, J. De Ridder, L. Longuevergne, C. Pagé, and P. Goderniaux. 2014. Investigating the respective impacts of groundwater exploitation and climate change on wetland extension over 150 years. Journal of Hydrology 509: 367-378.

Berardino, P., G. Fornaro, R. Lanari, and E. Sansosti. 2002. A new algorithm for surface deformation monitoring based on small baseline differential SAR interferograms. IEEE Transactions on Geoscience and Remote Sensing 40, no. 11: $2375-2383$.

Biot, M. 1941. General theory of three-dimensional consolidation. Journal of Applied Physics 12: 155-164.

Bruinsma, S., J.-M. Lemoine, R. Biancale, and N. Valès. 2010. CNES/GRGS 10-day gravity field models (release 2) and their evaluation. Advances in Space Research 45, no. 4: 587-601.

Calderhead, A.I., R. Martel, J. Garfias, A. Rivera, and R. Therrien. 2012. Pumping dry: an increasing groundwater budget deficit induced by urbanization, industrialization, and climate change in an over-exploited volcanic aquifer. Environmental Earth Sciences 66, no. 7: 1753-1767.

Calderhead, A.I., R. Therrien, A. Rivera, R. Martel, and J. Garfias. 2011. Simulating pumping-induced regional land subsidence with the use of InSAR and field data in the Toluca Valley, Mexico. Advances in Water Resources 34, no. 1: 83-97.

Castellazzi, P., N. Arroyo-Domínguez, R. Martel, A.I. Calderhead, J.C.L. Normand, J. Gárfias, and A. Rivera. 2016a. Land subsidence in major cities of Central Mexico: Interpreting InSAR-derived land subsidence mapping with hydrogeological data. International Journal of Applied Earth Observation and Geoinformation 47: 102-111.

Castellazzi, P., R. Martel, A. Rivera, J. Huang, P. Goran, A.I. Calderhead, E. Chaussard, J. Garfias, and J. Salas. 2016b. 
Groundwater depletion in Central Mexico: Use of GRACE and InSAR to support water resources management. Water Resources Research 52. DOI:10.1002/2015WR018211

Cazenave, A., and J.L. Chen. 2010. Time-variable gravity from space and present-day mass redistribution in the Earth system. Earth and Planetary Science Letters 298, no. 3-4: 263-274.

Chaussard, E., R. Bürgmann, M. Shirzaei, E.J. Fielding, and B. Baker. 2014a. Predictability of hydraulic head changes and characterization of aquifer-system and fault properties from InSAR-derived ground deformation. Journal of Geophysical Research, Solid Earth 119, no. 8: 94-106. DOI:10.1002/2014JB011266

Chaussard, E., S. Wdowinski, E. Cabral-Cano, and F. Amelung. 2014b. Land subsidence in Central Mexico detected by ALOS InSAR time-series. Remote Sensing of Environment 140: 94-106.

Cooper, H.H., and C.E. Jacob. 1946. A generalized graphical method for evaluating formation constants and summarizing well field history. Eos, Transactions American Geophysical Union 27: 526-534.

Crosetto, M., O. Monserrat, M. Cuevas-González, N. Devanthéry, and B. Crippa. 2016. Persistent Scatterer Interferometry: A review. ISPRS Journal of Photogrammetry and Remote Sensing 115: 78-89.

Döll, P., H. Hoffmann-Dobrev, F.T. Portmann, S. Siebert, A. Eicker, M. Rodell, G. Strassberg, and B.R. Scanlon. 2012. Impact of water withdrawals from groundwater and surface water on continental water storage variations. Journal of Geodynamics 59-60: 143-156.

Domenico, P.A., and M.D. Mifflin. 1965. Water from lowpermeability sediments and land subsidence. Water Resources Research 1, no. 4: 563-576. DOI:10.1029/ WR001i004p00563

Dragoni, W. 1998. Some considerations regarding the radius or influence or a pumping well. Hydrogéologie 3: 21-25.

Eicker, A., M. Schumacher, J. Kusche, P. Döll, and H. Schmied. 2014. Calibration/data assimilation approach for integrating GRACE data into the WaterGAP Global Hydrology Model (WGHM) using an Ensemble Kalman filter: First results. Surveys in Geophysics 35, no. 6: 1285-1309.

Famiglietti, J.S., and M. Rodell. 2013. Water in the balance. Science 340: 1300. DOI:10.1126/science.1236460

Famiglietti, J.S., M. Lo, S.L. Ho, J. Bethune, K.J. Anderson, T.H. Syed, S.C. Swenson, C.R. de Linage, and M. Rodell. 2011. Satellites measure recent rates of groundwater depletion in California's Central Valley. Geophysical Research Letters 38: L03403. DOI:10.1029/2010GL046442

Farinotti, D., L. Longuevergne, G. Moholdt, D. Duethmann, T. Molg, T. Bolch, S. Vorogushyn, and A. Guntner. 2015. Substantial glacier mass loss in the Tien Shan over the past 50 years. Nature Geoscience 8, no. 9: 716-722.

Feng, W., M. Zhong, J.-M. Lemoine, R. Biancale, H.-T. Hsu, and J. Xia. 2013. Evaluation of groundwater depletion in North China using the Gravity Recovery and Climate Experiment (GRACE) data and ground-based measurements. Water Resources Research 49, no. 4: 2110-2118.

Ferretti, A., G. Savio, R. Barzaghi, A. Borghi, S. Musazzi, F. Novali, C. Prati, and F. Rocca. 2007. Submillimeter accuracy of InSAR time series: Experimental validation. IEEE Transactions on Geoscience and Remote Sensing 45, no. 5: $1142-1153$.

Ferretti, A., C. Prati, and F. Rocca. 2001. Persistent scatterers in SAR interferometry. IEEE Transactions on Geoscience and Remote Sensing 39, no. 1: 8-20.

Ferretti, A., C. Prati, and F. Rocca. 2000. Nonlinear subsidence rate estimation using permanent scatterers in differential SAR interferometry. IEEE Transactions on Geoscience and Remote Sensing 38, no. 5: 2202-2212.

Forootan, E., R. Rietbroek, J. Kusche, M.A. Sharifi, J.L. Awange, M. Schmidt, P. Omondi, and J. Famiglietti. 2014.
Separation of large scale water storage patterns over Iran using GRACE, altimetry and hydrological data. Remote Sensing of Environment 140: 580-595.

Foster, S., H. Garduno, A. Tuinhof, K. Kemper, and M. Nanni. 2004. Urban Wastewater as Groundwater Recharge: Evaluating and Managing the Risks and Benefits. Washington, DC: The World Bank.

Freeze, A., and J.A. Cherry. 1979. Groundwater. Science. Prentice-Hall, $604 \mathrm{pp}$.

Galloway, D.L. 2014. Retrospective of InSAR/DInSAR contributions to hydrogeology by way of bibliographic search. In IEEE Proceedings of the Geoscience and Remote Sensing Symposium, July 13-18, Quebec City, Canada. DOI: 10.1109/IGARSS.2014.6947015

Galloway, D.L., and T.J. Burbey. 2011. Review-Land subsidence accompanying groundwater extraction. Hydrogeology Journal 19, no. 8: 1459-1486. DOI:10.1007/s10040011-0775-5

Galloway, D.L., and J. Hoffmann. 2007. The application of satellite differential SAR interferometry-derived ground displacements in hydrogeology. Hydrogeology Journal 15, no. 1: $133-154$.

Galloway, D.L., R. Bürgmann, E. Fielding, F. Amelung, and R.L. Laczniak. 2000. Mapping recoverable aquifer-system deformation and land subsidence in Santa Clara Valley, California, USA, using space-borne synthetic aperture radar. In Proceedings of the Sixth International Conference on Land Subsidence, September 25-29, Ravenna, Italy.

Galloway, D.L., K.W. Hudnut, S.E. Ingebritsen, S.P. Phillips, and G. Peltzer. 1998. Detection of aquifer system compaction and land subsidence using interferometric synthetic aperture radar, Antelope Valley, Mojave Desert, California. Water Resources Research 34, no. 10: 2573-2585.

Green, T.R., M. Taniguchi, H. Kooi, J.J. Gurdak, D.M. Allen, K.M. Hiscock, H. Treidel, and A. Aureli. 2011. Beneath the surface of global change: Impacts of climate change on groundwater. Journal of Hydrology 405, no. 3-4: 532-560.

Guntner, A., R. Schmidt, and P. Doll. 2007. Supporting largescale hydrogeological monitoring and modelling by timevariable gravity data. Hydrogeology Journal 15, no. 1: $167-170$.

Halford, K.J., W.D. Weight, and R.P. Schreiber. 2006. Interpretation of transmissivity estimates from single-well pumping aquifer tests. Groundwater 44: 467-471. DOI:10.1111/j.1745-6584.2005.00151.x

Hernandez-Marin, M., and T. Burbey. 2009. The role of faulting on surface deformation patterns from pumping-induced groundwater flow (Las Vegas Valley, USA). Hydrogeology Journal 17, no. 8: 1859-1875.

Heywood, C.E., D.L. Galloway, and S.V. Stork. 2002. Ground displacements caused by aquifer-system water-level variations observed using interferometric synthetic aperture radar near Albuquerque, New Mexico. U.S. Geological Survey Water-Resources Investigation Report 02-4235. http://nm.water.usgs.gov/publications/abstracts/wrir024235.html (accessed February 13, 2009).

Hoffmann, J., D.L. Galloway, and H.A. Zebker. 2003a. Inverse modeling of interbed storage parameters using land subsidence observations, Antelope Valley, California Water Resources Research 39, no. 2: SBH5-1-SBH5-10. DOI:10.1029/2001WR001252

Hoffmann, J., S.A. Leake, D.L. Galloway, and A.M. Wilson. 2003b. MODFLOW-2000 ground-water model - User guide to the subsidence and aquifer-system compaction (SUB) package. U.S. Geological Survey Open-File Report 2003-233, 44. http://pubs.usgs.gov/of/2003/ofr03-233/ (accessed February 13, 2009).

Hoffmann, J., H.A. Zebker, D.L. Galloway, and F. Amelung. 2001. Seasonal subsidence and rebound in Las Vegas Valley, Nevada, observed by synthetic aperture radar 
interferometry. Water Resources Research 37, no. 6: $1551-1566$.

Hu, L., and J. Jiao. 2015. Calibration of a large-scale groundwater flow model using GRACE data: A case study in the Qaidam Basin, China. Hydrogeology Journal 23, no. 7: $1305-1317$.

Huang, Z., Y. Pan, H. Gong, P.J.F. Yeh, X. Li, D. Zhou, and W. Zhao. 2015. Subregional-scale groundwater depletion detected by GRACE for both shallow and deep aquifers in North China plain. Geophysical Research Letters 42, no. 6: 1791-1799.

Huang, J., J. Halpenny, W. van der Wal, T.C. Klatt, S. James, and A. Rivera. 2012. Detectability of groundwater storage change within the Great Lakes Water Basin using GRACE. Journal of Geophysical Research - Solid Earth 117, B08401. DOI:10.1029/2011JB008876

Jacob, C.E. 1940. On the flow of water in an elastic artesian aquifer. Eos, Transactions American Geophysical Union 21, no. 2: 574-586. DOI:10.1029/TR021i002p00574

Konikow, L.F. 2015. Long-Term groundwater depletion in the United States. Groundwater 53: 2-9. DOI:10.1111/ gwat.12306

Konikow, L.F., and S.A. Leake. 2014. Depletion and capture: Revisiting "the source of water derived from wells". Groundwater 52, no. S1: 100-111. DOI:10.1111/gwat. 12204

Kruseman, G.P., and N.A. De Ridder. 1991. Analysis and Evaluation of Pumping Test Data. Wageningen, The Netherlands: International Institute for Land Reclamation and Improvement, Publication 47, 377.

Kundzewicz, Z.W., L.J. Mata, N.W. Arnell, P. Döll, P. Kabat, B. Jiménez, K.A. Miller, T. Oki, Z. Sen, and I.A. Shiklomanov. 2007. Freshwater resources and their management. In Climate Change 2007: Impacts, Adaptation and Vulnerability. Contribution of Working Group II to the Fourth Assessment Report of the Intergovernmental Panel on Climate Change, ed. M.L. Parry, O.F. Canziani, J.P. Palutikof, P.J. van der Linden, and C.E. Hanson, 173-210. Cambridge, UK: Cambridge University Press.

Lanari, R., P. Lundgren, M. Manzo, and F. Casu. 2004. Satellite radar interferometry time series analysis of surface deformation for Los Angeles, California. Geophysical Research Letters 31: L23613. DOI:10.1029/2004GL021294

Landerer, F.W., and S.C. Swenson. 2012. Accuracy of scaled GRACE terrestrial water storage estimates. Water Resources Research 48: W04531. DOI:10.1029/2011WR0 11453

Leake, S.A., and D.L. Galloway. 2007. MODFLOW groundwater model: User guide to the Subsidence and AquiferSystem Compaction Package (SUB-WT) for water-table aquifers. U.S. Geological Survey, Techniques and Methods 6-A23, 42.

Lohman, S.W. 1972. Ground-water hydraulics. U.S. Geological Survey, Professional Paper 708, 70.

Long, D., X. Chen, B.R. Scanlon, Y. Wada, Y. Hong, V.P. Singh, Y. Chen, C. Wang, Z. Han, and W. Yang. 2016. Have GRACE satellites overestimated groundwater depletion in the Northwest India aquifer? Scientific Reports 6: 24398.

Long, D., L. Longuevergne, and B.R. Scanlon. 2015. Global analysis of approaches for deriving total water storage changes from grace satellites. Water Resources Research 51: 2574-2594. DOI:10.1002/2014WR016853

Longuevergne, L., C.R. Wilson, B.R. Scanlon, and J.F. Crétaux. 2013. GRACE water storage estimates for the Middle East and other regions with significant reservoir and lake storage. Hydrology and Earth System Sciences 17, no. 12: 4817-4830.

Longuevergne, L., B.R. Scanlon, and R.W. Clark. 2010. GRACE hydrological estimates for small basins: Evaluating processing approaches on the high plains aquifer, USA. Water Resources Research 46: W11517. DOI:10.1029/2009WR008564

Lu, Z., and W.R. Danskin. 2001. InSAR analysis of natural recharge to define structure of a ground-water basin, San Bernardino, California. Geophysical Research Letters 28, no. 13: 2661-2664.

Marsily, G., F. Delay, J. Gonçalvès, P. Renard, V. Teles, and S. Violette. 2005. Dealing with spatial heterogeneity. Hydrogeology Journal 13, no. 1: 161-183.

Massonnet, D., and K.L. Feigl. 1998. Radar interferometry and its application to changes in the earth's surface. Reviews of Geophysics 36: 441-500.

Pail, R., R. Bingham, C. Braitenberg, H. Dobslaw, A. Eicker, A. Güntner, M. Horwath, E. Ivins, L. Longuevergne, I. Panet, and B. Wouters. 2015. Science and user needs for observing global mass transport to understand global change and to benefit society. Surveys in Geophysics 36, no. 6: 743-772.

Pasquali, P., P. Riccard, A. Cantone, M. Defilippi, F. Ogushi, and S. Galliano. 2011. Quantitative comparison of methods and sensors for monitoring land subsidence phenomena based on satellite SAR interferometric stacking. In Proceedings of the Geological Remote Sensing Group Annual Meeting 2011, December 7-9. Frascati, Italy: ESA ESRIN.

Pool, D.R. 2008. The utility of gravity and water-level monitoring at alluvial aquifer wells in southern Arizona. Geophysics 73, no. 6: WA49-WA59. DOI:10.1190/1.2980395

Pool, D.R., and J.H. Eychaner. 1995. Measurements of aquiferstorage change and specific yield using gravity surveys. Groundwater 33: 425-432. DOI:10.1111/j.1745-6584. 1995.tb00299.x

Ramillien, G., R. Biancale, S. Gratton, X. Vasseur, and S. Bourgogne. 2011. GRACE-derived surface water mass anomalies by energy integral approach: Application to continental hydrology. Journal of Geodesy 85, no. 6: $313-328$

Reeves, J.A., R. Knight, H.A. Zebker, P.K. Kitanidis, and W.A. Schreüder. 2014. Estimating temporal changes in hydraulic head using InSAR data in the San Luis Valley, Colorado. Water Resources Research 50: 4459-4473. DOI:10.1002/2013WR014938

Reeves, J.A., R. Knight, H.A. Zebker, W.A. Schreuder, P.S. Agram, and T.R. Lauknes. 2011. High quality InSAR data linked to seasonal change in hydraulic head for an agricultural area in the San Luis Valley, Colorado. Water Resources Research 47: 11.

Richey, A.S., B.F. Thomas, M.-H. Lo, J.T. Reager, J.S Famiglietti, K. Voss, S. Swenson, and M. Rodell. 2015. Quantifying renewable groundwater stress with GRACE. Water Resources Research 51, no. 7: 5217-5238.

Rocca, F., C. Prati, and A. Ferretti. 1997. An overview of ERSSAR interferometry. In Proceedings of the 3rd ERS Symposium on Space at the Service of Our Environment, xxvii-xxxvi. Florence, Italy: European Space Agency.

Rodell, M., I. Velicogna, and J.S. Famiglietti. 2009. Satellitebased estimates of groundwater depletion in India. Nature 460, no. 7258: 999-1002.

Rucci, A., A. Ferretti, A. Monti Guarnieri, and F. Rocca. 2012. Sentinel 1 SAR interferometry applications: The outlook for sub millimeter measurements. Remote Sensing of Environment 120: 156-163.

Sakumura, C., S. Bettadpur, H. Save, and C. McCullough. 2016. High-frequency terrestrial water storage signal capture via a regularized sliding window mascon product from GRACE. Journal of Geophysical Research, Solid Earth 121, no. 5: 4014-4030.

Samsonov, S., K. Tiampo, P.J. Gonzalez, V. Manville, and G. Jolly. 2010. Ground deformation occurring in the city of Auckland, New Zealand, and observed by Envisat interferometric synthetic aperture radar during 2003-2007. Journal of Geophysical Research, Solid Earth 115: 12. 
Save, H., S. Bettadpur, and B.D. Tapley. 2012. Reducing errors in the GRACE gravity solutions using regularization. Journal of Geodesy 86, no. 9: 695-711.

Scanlon, B.R., Z. Zhang, R.C. Reedy, D.R. Pool, H. Save, D. Long, J. Chen, D.M. Wolock, B.D. Conway, and D. Winester. 2015. Hydrologic implications of GRACE satellite data in the Colorado River Basin. Water Resources Research 51, no. 12: 9891-9903.

Scanlon, B.R., L. Longuevergne, and D. Long. 2012. Ground referencing GRACE satellite estimates of groundwater storage changes in the California Central Valley, USA. Water Resources Research 48: W04520. DOI:10.1029/2011WR011312

Schmidt, R., F. Flechtner, U. Meyer, K.H. Neumayer, C. Dahle, R. König, and J. Kusche. 2008. Hydrological signals observed by the GRACE satellites. Surveys in Geophysics 29, no. 4-5: 319-334.

Schmidt, D.A., and R. Bürgmann. 2003. Time dependent land uplift and subsidence in the Santa Clara Valley, California, from a large InSAR data set. Journal of Geophysical Research 108: 2416. DOI:10.1029/2002JB002267

Schuite, J., L. Longuevergne, O. Bour, F. Boudin, S. Durand, and N. Lavenant. 2015. Inferring field-scale properties of a fractured aquifer from ground surface deformation during a well test. Geophysical Research Letters 42: 10, 696-610, 703. DOI:10.1002/2015GL066387

Shamsudduha, M., R.G. Taylor, and L. Longuevergne. 2012. Monitoring groundwater storage changes in the highly seasonal humid tropics: Validation of GRACE measurements in the Bengal Basin. Water Resources Research 48: W02508. DOI:10.1029/2011WR010993

Siade, A.J., T. Nishikawa, D.L. Rewis, P. Martin, and S.P. Phillips. 2014. Groundwater-flow and land-subsidence model of Antelope Valley, California. U.S. Geological Survey, Scientific Investigations Report 2014-5166, 136.

Sun, A.Y., R. Green, S. Swenson, and M. Rodell. 2012. Toward calibration of regional groundwater models using GRACE data. Journal of Hydrology 422-423: 1-9. DOI:10.1016/j.jhydrol.2011.10.025

Tapley, B.D., S. Bettadpur, M. Watkins, and C. Reigber. 2004. The gravity recovery and climate experiment: Mission overview and early results. Geophysical Research Letters 31: L09607. DOI:10.1029/2004GL019920

Taylor, R.G., B. Scanlon, P. Doll, M. Rodell, R. van Beek, Y. Wada, L. Longuevergne, M. Leblanc, J.S. Famiglietti, M. Edmunds, L. Konikow, T.R. Green, J.Y. Chen, M. Taniguchi, M.F.P. Bierkens, A. MacDonald, Y. Fan, R.M. Maxwell, Y. Yechieli, J.J. Gurdak, D.M. Allen, M. Shamsudduha, K. Hiscock, P.J.F. Yeh, I. Holman, and H. Treidel. 2013. Ground water and climate change. Nature Climate Change 3, no. 4: 322-329.
Terzaghi, K. 1925. Principles of soil mechanics. IV: settlement and consolidation of clay. Engineering News-Record 95, no. 3: 874-878.

Thales Alenia Space. 2010. Assessment of a next generation gravity mission for monitoring the variations of Earth's gravity field. Final Report SD-RP-AI-0688, 160.

Theis, C.V. 1935. The relation between the lowering of the piezometric surface and the rate and duration of discharge of a well using groundwater storage. American Geophysical Union Transactions 16: 519-524.

Todd, D.K. 1980. Groundwater Hydrology, 2nd ed. New York: Wiley, 535p.

Tourian, M.J., O. Elmi, Q. Chen, B. Devaraju, S. Roohi, and N. Sneeuw. 2015. A spaceborne multisensor approach to monitor the desiccation of Lake Urmia in Iran. Remote Sensing of Environment 156: 349-360.

Van der Kamp, G. 1985. Brief quantitative guidelines for the design and analysis of pumping test. In Hydrogeology in the Service of Man, 197-206. Cambridge, MA: 18th Congress of the International Association of Hydrogeologists.

Watkins, M.M., D.N. Wiese, D.N. Yuan, C. Boening, and F.W. Landerer. 2015. Improved methods for observing Earth's time variable mass distribution with GRACE using spherical cap mascons. Journal of Geophysical Research, Solid Earth 120, no. 4: 2648-2671.

Watkins, M., F. Flechtner, P. Morton, and F. Webb. 2013. Status of the GRACE follow-on mission. Geophysical Research Abstracts 17: EGU2015-6616.

Xie, H., L. Longuevergne, C. Ringler, and B.R. Scanlon 2012. Calibration and evaluation of a semi-distributed watershed model of Sub-Saharan Africa using GRACE data. Hydrology and Earth System Sciences 16, no. 9: 3083-3099.

Xu, W.B., Z.W. Li, X.L. Ding, C.C. Wang, and G.C. Feng. 2012 Application of small baseline subsets D-InSAR technology to estimate the time series land deformation and aquifer storage coefficients of Los Angeles area. Chinese Journal of Geophysics-Chinese Edition 55: 452-461.

Yan, T.T., and T.J. Burbey. 2008. The value of subsidence data in ground water model calibration. Groundwater 46, no. 4: $538-550$

Zaitchik, B.F., M. Rodell, and R.H. Reichle. 2008. Assimilation of GRACE terrestrial water storage data into a land surface model: Results for the Mississippi River Basin. Journal of Hydrometeorology 9, no. 3: 535-548.

Zhang, M., T.J. Burbey, V.D.S. Nunes, and J. Borggaard. 2014 A new zonation algorithm with parameter estimation using hydraulic head and subsidence observations. Groundwater 52: 514-524. DOI:10.1111/gwat.12102 